\title{
Teaching Workplace Skills Through Integrative Exercises
}

Susan P. Eisner, (E-mail: seisner@ramapo.edu), Ramapo College of New Jersey

\begin{abstract}
This paper presents a set of three integrative exercises created to help college students develop workplace skills through simulation. Interviewing, listening, providing feedback, setting goals, empowering, coaching, managing change, handling conflict, and making decisions are clustered and modeled at intervals that synthesize course learning.
\end{abstract}

\section{Introduction}

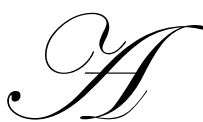

cademic literature and AACSB International standards support inclusion of active learning opportunities for students in college teaching (AACSB International, 20003). Both academics and practitioners have expressed the need for contemporary workers to possess interpersonal and communication skills (Wardrope, 2000; Business-Higher Education Forum, 1999). Business schools have been criticized for not preparing graduates for the workplace (Richards-Wilson, 2002). In the wake of recent highly publicized corporate scandals, the need for business schools to do better at exploring and teaching human dynamics has been cited (Dill, 2002). Leadership is the program in highest demand at Harvard's Kennedy School of Government (Speaker Remarks, 2003). An industry of "coaches" has emerged to customize development of core skills among managers (Morris, 2000; Smith \& Sandstrom, 1999).

Against this backdrop, many business school instructors seek pedagogy that will help their students gain competence with such skills. In teaching the undergraduate Organizational Behavior course at Ramapo College of New Jersey, that desire was particularly timely. Several of our students said that they could not distinguish the Organizational Behavior course from the Fundamentals of Management course intended as its precursor. To these students, both courses seemed to have similar central concepts.

In response, faculty re-examined the two courses. They concluded that the Fundamentals of Management course should present the foundation for the Organizational Behavior course, which should then apply the concepts that had been learned to practical scenarios. Organizational Behavior would be the skill-building course.

From this vantage point, various learning methods infused with the textbook were accessed. The primary text we use (Schermerhorn et. al., Organizational Behavior, 2003) contains a variety of self-assessment inventories, experiential exercises, and cases through which students can increase awareness of skills and their application. Positive student response to these assignments encouraged me to seek ways to extend the learning further. While students did appear to be progressing one skill at a time, too many students appeared to be leaving the last skill learned behind when attending to the next new skill presented. Could creating a set of integrative exercises simulating a skill cluster learned over a series of weeks counter that tendency? The series of three integrative exercises created as a result appear to be doing just that.

\section{Integration}

Designing the integrative exercises began with identifying groups of skills that corresponded to material the course covers over each of three five-week periods that together comprise our fifteen-week semester. Supplementary texts whose focus includes building such skills were identified. Chief among these were Robbins and Hunsaker's Training in InterPersonal Skills (1996 and 2003), and Bovee and Thill's Business Communication Today (2003). 
A hypothetical workplace setting with which students could relate, in which they would simulate target skills, was then selected. A series of three simulations, each picking up where the previous one had left off, and each occurring at the same hypothetical workplace setting, was conceived. Each of these three integrative exercises was titled to convey its focus.

Handouts were then prepared that described each exercise, detailed and referenced text sources for each skill to be simulated, and provided checklists for use in assessing the simulated skills. Reading lists included the supplementary texts. The course syllabus noted the title of each exercise and the date it would be held. Exams incorporated the integrative exercises among learning to be assessed. The Assignment Description section of the syllabus introduced students to the simulations, and specified expectations for participation. Figure 1 contains that description:

Figure 1: Integrative exercises as introduced in the syllabus' assignment description section.

\section{Integrative Exercises}

These three sessions provide the opportunity for in-class active learning, and are a special feature of the course. You will develop proficiency with several skills that practitioners use to handle organizational behavior. You will apply these skills to workplace situations, work in groups that provide peer learning, and receive constructive feedback.

Integrative exercises are workshops designed to develop your competence and confidence in the targeted areas, and are graded for participation. At the session before each exercise is held, you will receive specific background and be assigned a role to simulate that applies skills you have been learning. Attendance, preparation, and participation are expected and will be noted (low preparation or contribution reduce one's course participation grade; strong preparation or contribution will enhance it). Absences not medically documented will reduce one's grade.

\section{Scenario}

The hypothetical workplace setting for this series of integrative exercises is a nationally-known technology store located in a near-by suburban mall. It is highly likely that all students are familiar with such a store and such a setting. Most of the students probably have shopped in such a store. Some probably have worked in such a store.

Students are introduced to that setting in preparation for the first integrative exercise. They are told that the details of each exercise will be presented in advance of that exercise, to maximize focus on the scenario at hand. Advance knowledge of upcoming developments that subsequent simulations will focus on might be distracting, and would dilute the reality-based foundation for the exercises. Why should students have knowledge of future developments when role-playing, when those they were simulating would not have that knowledge in such situations?

\section{Integrative Exercise 1: Getting To Know You}

The first integrative exercise is titled "Getting To Know You." Students are told that the General Manager of a leading, nationally known technology store at a nearby mall has been looking for six months for a Customer Service Manager for the store. The two previous Customer Service Manager left to work for this store's chief competitor, which is eroding this store's market share and pays its employees more than this store does. Turnover in this position has been high.

Students are further informed that the General Manager is busy planning how to keep this store viable, and cannot give Customer Service the attention it requires. In the absence of a Customer Service Manager, the General Manager has overseen the department, and so is familiar with its staff and functions. The Customer Service Manager will oversee a staff of seven employees. 
Finally, students learn that the General Manager is about to interview a candidate for the job who has long Customer Service experience at an internationally known, established retail store. That store does not deal in technology products, and is located in an urban setting about 45 minutes away. The candidate's current position, Assistant Manager of Customer Service, is one level lower than the position the General Manager seeks to fill. The department the candidate serves in, though, has twenty employees. S/he has been steadily promoted and is highly regarded there.

This first integrative exercise simulates the interview between the General Manager and candidate for Customer Service Manager, with the goal of determining whether or not the candidate will become the next Customer Service Manager. The simulation occurs in groups of four students. All groups simulate the interview at the same time. Students are focused on their own interaction and performance; all are engaged throughout. At the session preceding the simulation, each student is assigned to one of the following roles: interviewer (General Manager), interviewee (candidate for Customer Service Manager), coach/observer for interviewer, or coach/observer for interviewee. If there are an odd number of students, a group of three students will simulate the interviewer (General Manager), interviewee (candidate for Customer Service Manager), and coach/observer for interviewer and for interviewee.

Students are told that three skill sets will be simulated in this exercise: interviewing, listening, and providing feedback. They are referred to text material that covers these skills. That material serves as the basis for the instructor's preparation of skill assessment checklists that itemize each skill as it will be simulated and assessed. Students are provided with handouts that summarize the background they are told verbally in class, contain the checklist for the skills to be simulated, reference the text upon which the checklist is based, and present the format the simulation will follow. Excerpts from the handouts students receive to prepare for the first integrative exercise appear in Figures 2 and 3.

\section{Integrative Exercise 2: Welcome Aboard}

The second integrative exercise is titled "Welcome Aboard." It is conducted about five weeks after the first simulation. Students are told that the General Manager decided to offer the position of Customer Service Manager to the candidate, who accepted. The Customer Service Manager will report to the General Manager. This exercise simulates a meeting between General Manager and Customer Service Manager on their first day working together, with the goal of establishing the foundation for productivity and satisfaction.

Students are told that the General Manager has offered the candidate the position of Customer Services Manager, and that the offer has been accepted. They are reminded that the General Manager knows that the new Customer Service Manager has not previously performed at this level, at this company, or at a store that primarily sells technology products. They are reminded that the General Manager is concerned about the competitive vulnerability of this store. It is important to the General Manager that the new Customer Service Manager leads the department to strong performance, and remains in the position. The General Manager wants to be sure that from the start the new Customer Service Manager understands the position's responsibilities and authority, knows s/he has the General Manager's support and availability, and is eager to perform at a high level and succeed.

Students are further informed that the new Customer Services Manager is aware that $\mathrm{s} / \mathrm{he}$ has left an established flagship store for this opportunity to serve as a manager, that s/he has not worked in this location or type of store before, that turnover has been high, and that competition is strong. The Customer Services Manager wants to be sure that the General Manager has provided the information, access, and conditions necessary for success from the start. The Customer Services Manager wants the risk taken in accepting this position to have been wise. to meet.

Students then learn it is the Customer Service Manager's first day at work. The General Manager has asked

The second integrative exercise simulates that first day meeting between the General Manager and the new Customer Service Manager. As with the first integrative exercise, the simulation occurs in groups of four students. 
All groups simulate the meeting at the same time. At the session preceding the simulation, each student is assigned to one of the following roles: boss (General Manager), new hire (Customer Service Manager), coach/observer for General Manager/boss, or coach/observer for Customer Service Manager/new hire. If there are an odd number of students, a group of three students will simulate the boss (General Manager), new hire (Customer Service Manager), and coach/observer for boss and new hire. Wherever possible, students who were coach/observers in integrative exercise 1 are assigned the role of boss or new hire in integrative exercise 2.

Figure 2: Handout with simulation and format for integrative exercise 1.

\section{Integrative Exercise 1: Getting To Know You}

$\underline{\text { Simulation }}$

You will role-play and assess the interview between the interviewer (General Manager) and the interviewee (candidate for Customer Service Manager), enacting the part to which you have been assigned.

\section{Format}

1. Preparation (15 minutes): Each group breaks into pairs that plan strategy for the interview. The interviewer meets with his/her coach/observer, and the interviewee meets with his/her coach/observer. In a three-person group, the coach/observer meets with the interviewer and then meets separately with the interviewee. The pairs do not listen to each other's plans.

2. Interview (15 minutes): The interviewer and interviewee role-play the interview, applying the strategy they have planned with their coach/observers. Each observer notes and assesses the interviewing and listening performance of the person s/he coached in the preparation stage, using the skill assessment checklist all received.

3. Recommendation (5 minutes): The interviewer recommends to his/her coach/observer whether the candidate should be hired, and why; the coach/observer confirms or disagrees with the recommendation. The interviewee recommends to his/her coach/observer whether to accept the position if it is offered, and why; the coach/ observer confirms or disagrees with the recommendation.

4. Feedback (15 minutes): The coach/observer provides feedback to the person coached/observed regarding the observed performance, using notations made on the skill assessment checklist all received. Then those who have received feedback tell their coach/observer how well they provided feedback, using the checklist as criteria.

5. Poll (5 minutes): All interviewers anonymously report to the instructor whether they would hire the candidate. All candidates anonymously report whether they would accept the position. All coach/observers anonymously report whether they agree with the decision of the person coached/observed. The instructor reports the results.

6. Lessons Learned (15 minutes): Each student reports to the class on one assessed characteristic that is a strength $\mathrm{s} / \mathrm{he}$ possesses, one assessed characteristic that is identified for improvement, and the most important lesson $\mathrm{s} / \mathrm{he}$ learned from performing the simulation.

Students are told that three skill sets will be simulated in this exercise: goal-setting, empowering, and coaching. As when preparing for integrative exercise 1, students are referred to text material that covers the skills to be simulated and are provided with handouts to background their preparation for the simulation. Excerpts from the handouts students receive to prepare for the second integrative exercise appear in Figures 4 and 5. 
Figure 3: Handout with skill assessment checklist for integrative exercise 1.

\section{Integrative Exercise 1: Getting To Know You}

$\underline{\text { Skill Assessment Checklist }}$

Key characteristics of skills simulated in this exercise are itemized below. Write "yes" next to each characteristic that the observed person displays. Write "no" next to each characteristic that the observed person does not display.

Criteria

Interviewing (interviewer and interviewee are rated by their coach/observers)

- Assesses capability (technical ability to do the job)

- Assesses compatibility (chemistry; cultural fit)

- Assesses commitment (staying power and performance expectations)

- Assesses contribution (value added)

- Assesses credibility (full disclosure)

Listening (interviewer and interviewee are rated by their coach/observers)

- Listens actively (deliberately concentrates)

- Listens patiently (does not interrupt; hears before speaks)

- Listens objectively (hears all content before evaluating any)

- Listens for content (reacts to message rather than to messenger)

- Listens empathetically (sees message through messenger's eyes)

- Asks clarifying questions (assures message is understood)

- Paraphrases (restates message received)

- Provides reflective feedback (responds to message)

- Takes notes (jots down key points)

Providing Feedback (coach/observer is rated by interviewer or interviewee they coached/observed; interviewer and interviewee are rated by their coach/observer)

- Focuses on specific behaviors (is not general)

- Is impersonal and work-related (focuses on task and behavior)

- Is descriptive and non-judgmental (explains consequences of actions)

- Positions remarks toward achieving recipient's goals (provides motivation)

- Is concise, complete, and ensures understanding (asks for paraphrasing)

- Includes both positives and negatives (is balanced)

- Delivers negative feedback in constructive terms (tells how to do it right)

- Is sure recipient can accomplish desired performance (don't ask the impossible)
Role Being Assessed

Interviewer Interviewee

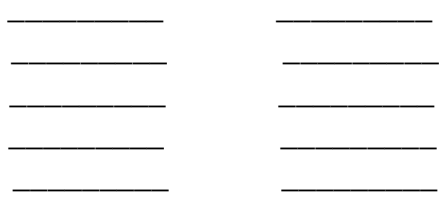

Interviewer

Interviewee

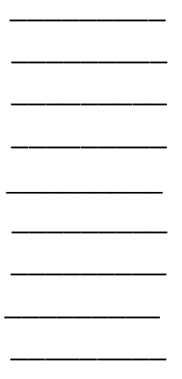

Interviewer's

Coach/

Observer

Interviewee's

Coach/

Observer 
Figure 4: Handout with simulation and format for integrative exercise 2.

Simulation

\section{Integrative Exercise 2: Welcome Aboard}

You will role-play and assess the meeting between the boss (General Manager) and the new hire (Customer Service Manager), enacting the part to which you have been assigned.

Format

1. Preparation (15 minutes): Each group breaks into pairs that plan meeting strategy. The boss meets with his/her coach/observer, and the new hire meets with his/her coach/observer. In a three-person group, the coach/observer meets with the boss and then meets separately with the new hire. The pairs do not listen to each other's plans.

2. Meeting (15 minutes): The boss and new hire enact the strategy they have planned with their coach/observer. Each observer notes and assesses the goal-setting and empowering performance of the person s/he coached in the preparation stage, using the skill assessment checklist all received.

3. Coaching (15 minutes): Each coach/observer tells the person observed how to maximize future performance, using the notated checklist.

4. Reflection (10 minutes): The boss and new hire note the coaching performance of his/her coach/observer, using the skill assessment checklist. Each then tells his/her coach/observer how to maximize future coaching.

5. Lessons Learned (15 minutes): Each student reports to the class on one assessed characteristic that is a strength $\mathrm{s} / \mathrm{he}$ possesses, one assessed characteristic identified for improvement, and the most important lesson learned.

\section{Integrative Exercise 3: Trouble in Paradise}

The third integrative exercise is titled "Trouble in Paradise." It is held at the end of the course, about five weeks after the second simulation. Students are told that the new Customer Service Manager has now been on the job for one month. The General Manager is pleased with the results, as indicators look positive. Customer complaints and returns are down, repeat business and referral business are up, fewer "freebies" have been given to customers, and a system tracking and evaluating customer feedback has been designed.

Students are told that two employees of the Customer Service staff of seven have just come to see the General Manager. Saying that they represent the department's staff, they report that their new manager is unacceptable. They claim that s/he lacks the management skill the position requires, does not fit the company culture, does not understand the customers, and is a Theory $\mathrm{X}$ manager in a Theory $\mathrm{Y}$ unit.

Students are further informed that these two employees are long-time Customer Service staffers. They present the General Manager with an ultimatum. They say, "Either fire the new manager or the Customer Service staff will leave."

Finally, students learn that the General Manager responds to this development by calling upon a team of management consultants. They have been selected for their expertise in managing change and handling conflict. Having been briefed on the situation by the General Manager, the management consultants are ready to discuss the situation in the Customer Service department and recommend next steps to the General Manager.

The third integrative exercise simulates that meeting between the management consulting team, with the goal of determining recommendations to present to the General Manager. The simulation occurs in groups of three or five students; an odd number is used so that deadlock can be broken if the group takes a vote. All groups simulate the meeting at the same time. 
Figure 5. Handout with skill assessment checklist for integrative exercise 2.

\section{Integrative Exercise 2: Welcome Aboard}

Skill Assessment Checklist

Key characteristics of skills simulated in this exercise are itemized below. Write "yes" next to each characteristic that the observed person displays. Write "no" next to each characteristic that the observed person does not display.

Criteria

Goal-setting (boss and new hire are rated by their coach/observer)

- Specifies objectives and tasks

- Explains how performance will be evaluated

- Clarifies standards and targets

- Identifies timeframe

- Seeks employee input re: goals

- Sets specific goals

- Designs challenging but attainable goals

- Prioritizes goals

- Rates difficulty of goals

- Confirms process and resources

Empowering (boss and new hire are rated by their coach/observer)

- Allocates duties

- Delegates authority

- Assigns responsibility

- Creates accountability

- Clarifies tasks

- Specifies discretion

- States expectations

- Sets deadlines

- Establishes adequate and appropriate controls

- Gets employee input

Coaching (coach/observer is rated by boss or new hire coached/observed)

- Listens actively

- Facilitates, does not tell

- Is positive and encouraging

- Positions mistakes as opportunity to learn

- Focuses on helping the one coached to improve

- Validates successes of the one coached

- Sets attainable goals

- Models desired qualities and behavior

- Helps the one coached identify and weigh alternatives

- Has the one coached recommend/conclude
Role Being Assessed

Boss

New Hire

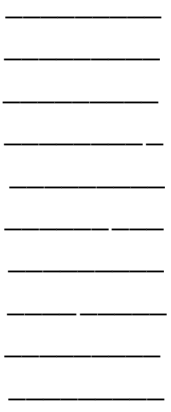

Boss

New Hire

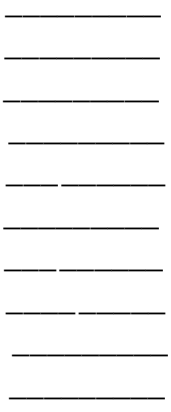

Boss'

Coach

New Hire's

Coach 
Students are told that three skill sets will be simulated in this exercise: managing change, handling conflict, and making decisions. As when preparing for integrative exercises 1 and 2, students are referred to text material that covers the skills to be simulated and are provided with handouts to background their preparation for the simulation. Excerpts from the handouts students receive to prepare for the third integrative exercise appear in figures 6 and 7.

Figure 6. Handout with simulation and format for integrative exercise 3.

Simulation

\section{Integrative Exercise 3: Trouble in Paradise}

You will role-play the meeting between the management consulting team in which recommendations for the General Manager are determined. Following the simulation, your group will report and explain its recommendations.

Format

1. Meeting (15 minutes): The management consulting team discusses the Customer Service developments.

2. Decision-making (15 minutes): The management consulting team determines the recommended next steps it will present to the General Manager.

3. Recommendation (15 minutes): One member of each group reports and justifies its recommendations to the class.

4. Poll (5 minutes): All students anonymously report to the instructor on five items: 1) did they agree with their group's decision, 2) did they express themselves in the group, 3) was their input considered by the group, 4) did all group members participate equally, and 5) did the group reach consensus. The instructor reports the results.

5. Assessment (5 minutes): All students assess their group's performance, using the checklist all received.

6. Lessons Learned (15 minutes): Each student reports to the class one simulated characteristic that was a strength of his/her group, one simulated characteristic the group should improve, and the most important lesson learned.

\section{Assessing Learning}

Learning achieved through the integrative exercises is assessed three ways. As shown in Figures 2, 4, and 6 , each of the exercises concludes with each student giving an oral report that synthesizes insights gained. This is an informal oral report, presented from the student's seat, to maintain focus on content rather than on technical aspects of formal presentation. Feedback is individual and immediate, allowing the instructor to access learning opportunities that occur.

A second way learning is assessed is through inclusion of questions covering simulated skills in the objective sections of mid-term and final exams covering the part of the course during which the skill sets were simulated. Additionally, essay questions on those exams assess student learning in a more open-ended format. Including material on exams covered in integrative exercises has several purposes. First, inclusion on exams underscores that the simulations are vehicles that facilitate important learning. Further, learning is reinforced as students reflect upon, synthesize, and express insights gained from the simulations some time after participating in them. Representative essay questions appear in Figure 8. 
Figure 7. Handout with skill assessment checklist for integrative exercise 3.

\section{Integrative Exercise 3: Trouble in Paradise}

$\underline{\text { Skill Assessment Checklist }}$

Key characteristics of skills simulated in this exercise are itemized below. Write "yes" next to each characteristic your group considered or displayed when simulating the management consulting team. Write "no" next to each characteristic your group did not consider or display.

Criteria

Group Considers

Managing Change

- Implements change using three stages (unfreeze, change, and refreeze)

- Decides the best change strategy (force-coerce, rational persuasion, or shared power)

- Minimizes resistance to change (provide benefit, compatibility, simplicity, triability, and/or acceptable change agent)

- Overcomes resistance to change (educate/communicate, participate/support, facilitate, negotiate/agree, manipulate/coopt, and/or coerce)

Handling Conflict

- Identifies the conflicted parties

- Understands their frames of reference, to see the situation as they do

- Determines whether the conflict is substantive or emotional

- Clarifies management objectives and priorities

- Establishes what management is willing to spend and/or lose

- Weighs indirect conflict management approaches (reduced interdependence, appeals to common goals, hierarchical referral, alternating scripts/myths, or removing conflict leaders)

- Contemplates direct conflict management approaches (avoidance/withdrawal, compromise/share, accommodate/smooth, compete/force, collaborate/problem-solve, or authority/command)

Displays

Group

Making Decisions

- Identifies and clarifies the situation the decision addresses

- Puts the decision to be made in the form of a question

- Lists all the facts, and identifies any necessary information that is missing

- Collects any necessary information that is missing

- Generates a range of alternatives, using brainstorming techniques

- Establishes criteria for judging alternatives, including probability of success

- Evaluates all alternatives objectively, applying the criteria established

- Selects the optimal alternative, seeking consensus

- Formulates a specific implementation plan with assigned tasks and timetable

- Establishes a mechanism for follow up and any corrective action needed 
Figure 8. Representative exam essay questions covering integrative exercise. Sample Midterm Exam Essay Question Covering Integrative Exercise 1

We have conducted our first integrative exercise, in which your group simulated the manager of a leading technology store interviewing a candidate for the position of Customer Service Manager. This exercise built and assessed interviewing, listening, and providing feedback skills. Drawing upon course material used to prepare for and role-play this exercise, explain three specific characteristics of each of the simulated skills. Then give one related specific example from the integrative exercise or other course material for each skill, and one critical thinking question stimulated by your exposure to the skill in that exercise. Include an introduction. Provide a thoughtful and specific conclusion containing the most important lesson learned from performing this simulation. Use this format:

$\underline{\text { Introduction }}$

\section{$\underline{\text { Skills simulated }}$}

1. Interviewing (three specific characteristics, one course example, and one critical thinking question)

2. Listening (three specific characteristics, one course example, and one critical thinking question)

3. Providing feedback (three specific characteristics of effective feedback, one course example, and one critical thinking question)

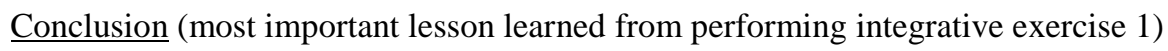

\section{Sample Final Exam Essay Question Covering Integrative Exercise 3}

In our third integrative exercise, your group simulated a meeting of a consulting team hired by the General Manager of a leading technology store regarding a threat by members of the Customer Services department to quit if the new Customer Service Manager is not fired. Among the simulated skills were managing change and handling conflict. Drawing upon course material used to prepare for and role-play this exercise, explain three specific characteristics of each of the simulated skills. Then recommend the action the General Manager should take, and defend it using specific learning in this course. Include an introduction. Provide a thoughtful and specific conclusion containing the most important lesson learned from performing this simulation. Use this format:

\section{$\underline{\text { Introduction }}$}

\section{$\underline{\text { Simulation }}$}

1. Conflict management skills (three specific characteristics, one course example, and one critical thinking question)

2. Change management skills (three specific characteristics, one course example, and one critical thinking question)

3. Recommendation to General Manager

4. Support for that recommendation, with text/course material as proof

Conclusion (most important lesson learned from performing integrative exercise 3) 


\section{Results}

The primary impetus to create a series of integrative exercises simulating skill clusters learned over a series of weeks was to create pedagogy to serve the curricular objectives of our Organizational Behavior course. Textlinked assignments appeared to be providing a conceptual foundation of requisite skills. But many students appeared to be absorbing the skills as if they were theories to memorize and observe from a distance, rather than as competencies to infuse and apply themselves. Moreover, skills appeared to be frequently left behind when the next new skill was presented. Students seemed to be experiencing skills in isolation, rather than as skill sets to be drawn upon.

Might creating a set of integrative exercises simulating a skill cluster learned over several weeks counter that tendency? Outcomes of many classes over several years suggest a positive answer. Results from the polling and lesson learned stages of the simulations indicate that students understand and apply characteristics of the simulated skills. Answers to objective and essay questions on subsequent exams indicate that learning is retained. Attendance is essentially universal for integrative exercises. Even students who do not regularly prepare for class come prepared. Students who do not regularly speak up in class participate actively. Many students with experiences that relate to simulated skills share them in later sessions, providing opportunity for further analysis and application.

An important outcome of creating these exercises was unanticipated. It relates to the instructor, rather than to the students. The process of creating the simulations requires the instructor to crystallize specific and actionable characteristics of the skill sets to be modeled. For me, that process of translating intricate competencies into concrete attributes and steps greatly facilitated the ability to explain them to students in a way that could achieve progress.

\section{Discussion}

Active learning would seem to bear a kind of double-bind. On the one hand, the enhanced engagement of the learner that is its foundation increases the ability of an instructor to reach the learner. The ability of a student to be a participatory learner relating to material, approaching it with others, contemplating it reflectively, experiencing multiple ways of learning, and receiving prompt feedback appears to increase the student's interest and retention. It is for this reason that academic standards ranging from those of AACSB International to the Seven Principles in Action identified by the American Association for Higher Education promote active learning (AACSB International, 2003; Page and Mukherjee, 2000). On the other hand, education students perceive as entertainment may be dismissed as unimportant and not receive their full attention.

Creating a series of integrative exercises that are effective, then, is not easy. The steps detailed above identifying scenarios all students can relate to, itemizing skill sets corresponding to course material, conceiving of simulations merging scenario with target skills, finding and referencing supplementary texts that focus on the skills, designing materials to prepare and assess performance, updating syllabi and reading lists, monitoring and responding to teaching opportunities that arise during the simulation, and implementing means to determine learning - are labor-intensive and time-consuming.

Moreover, the process is incomplete without the instructor's positioning the simulations to students. I take great care to convey the simulations as vehicles to enhance cognition and ability. Students understand that we do not do the exercises to take a break from the hard work of furthering their education. We do them as a way to accomplish complex and essential learning.

Inclusion of the integrative exercises in the syllabus along with all other topics and assignments is a start. Distribution of detailed, well prepared handouts and reading lists goes far. Incorporating the integrative exercises on mid-term and final exams goes even further. Verbally positioning the exercises as significant learning opportunities provides additional reinforcement.

A limitation of the integrative exercises presented here is that instructors may vary in the skill sets they prioritize to teach, the texts they use, and characteristics they emphasize when teaching target skills. Additionally, 
classes may vary in the scenarios students relate to. It is important to note, then, that the three simulations detailed in this paper - Getting To Know You, Welcome Aboard, and Trouble in Paradise - may not be an exact "fit" for those interested in replicating such pedagogy. These simulations are intended, instead, as a template. They demonstrate a process and ingredients with which an instructor can create integrative exercises tailored to their own curriculum and students.

When approached as a template, integrative exercises present a pedagogical tool with many applications. I have adapted them, for instance, for use in the undergraduate Business Communication course, the undergraduate Contemporary Arts Management course, the graduate Managerial Communication course, and in training sessions for practitioners. Skill sets and scenario simulated change to reflect the different curricula and students. Outcomes, however, have remained the same.

\section{Conclusion}

Although creating a series of integrative exercises that are effective is not easy, instructors seeking to apply such pedagogy are likely to find the effort worthwhile. The simulations appear to heighten student interest, awareness, development, and retention of core skills. The process of conceiving, incorporating, positioning, delivering, and assessing them appears to heighten instructor ability to present core skills in ways that students can and want to grasp. Instructors seeking to adapt similar pedagogy may want to consider an unexpected ripple effect, though. Several students who have taken my Organizational Behavior course have enrolled in my other courses, seeking additional integrative exercises. Those needs deserved responsive action. Integrative exercises have since become a feature of many of those courses.

\section{References}

1. AACSB International - The Association to Advance Collegiate Schools of Business. (2003, March 10). Proposed eligibility procedures and standards for business accreditation. Retrieved August 13, 2003, from http://www.aacsb.edu/conferences/events/seminars.asp.

2. $\quad$ Bovee, C., Thill, J., \& Schatzman, B. (2003). Business Communication Today ( $7^{\text {th }}$ ed.). Prentice Hall.

3. Business-Higher Education Forum. (1999). Spanning the chasm: A blueprint for action. Academic \& corporate collaboration: Key to preparing tomorrow's high-performance workforce. Retrieved August 12, 2003, from ERIC database.

4. Dill, W. (2002, Fall). Beyond codes and courses. Selections 2 (2), 21 (3). Retrieved November 30, 2003, from Proquest database.

5. Morris, B. (2000, February 21). So you're a player. Do you need a coach? Fortune 141 (4), 144 (7). Retrieved November 30, 2003, from Proquest database.

6. Page, D., \& Mukherjee, A. (2000). Improving undergraduate student involvement in management science and business writing courses using the seven principles in action. Education, 120 (3), 547 (12).

7. Richards-Wilson, S. (2002, May-June). Changing the way MBA programs do business - lead or languish. Journal of Education for Business, 77 (5), 296 (5). Retrieved November 30, 2003, from Proquest database.

8. $\quad$ Robbins, S., \& Hunsaker, P. (2003). Training in InterPersonal Skills ( $3^{\text {rd }}$ ed.). Prentice Hall.

9. $\quad$ Robbins, S., \& Hunsaker, P. (1996). Training in InterPersonal Skills ( $2^{\text {nd }}$ ed). Prentice Hall.

10. Schermerhorn, J., Hunt, J., \& Osborn. R. (2003). Organizational Behavior ( $8^{\text {th }}$ ed). Wiley.

11. Smith, L., \& Sandstrom, J. (1999, October-December). Executive leadership coaching as a strategic activity. Strategy \& Leadership 27 (6), 33 (4). Retrieved November 30, 2003, from Proquest database.

12. Speaker Remarks (2003, June). Conversations to move your mission forward. Plenary Session at Harvard University, Kennedy School of Government, Alumni Refresher.

13. Wardrope, W. J. (2002). Department chairs' perceptions of the importance of business communication skills. Business Communication Quarterly, 65 (4), 60 (13). 